\title{
The Positive Career Goal Discrepancy Scale: Development and Initial Validation
}

\begin{abstract}
The 15-item Positive Career Goal Discrepancy Scale was developed to assess emerging adults' appraisals of the extent to which their current career progress exceeds their set career goals. We generated 32 items based on a literature review, focus groups, and expert reviews, used EFA $\left(N=244, M_{\text {age }} 18.7\right.$ years; $65 \%$ women $)$ to reduce the number of items, and CFA $\left(N=254, M_{\text {age }} 18.7\right.$ years; $68 \%$ women $)$ to confirm the factor structure and demonstrate superior reliability at the total score level $(\omega$ reliability $=.91)$. Validity testing demonstrated that the scale was distinct from a measure of negative career goal discrepancy and related, as expected, to constructs in the nomological net: correlated positively with career satisfaction and optimism, and negatively with negative career goal discrepancy. The scale is a useful addition to the career literature and is likely to stimulate research into positive career goal progress in young people.
\end{abstract}

Keywords: positive career goal discrepancy, career goals, scale development, emerging adults, career development. 
The Positive Career Goal Discrepancy Scale: Development and Initial Validation

Emerging adults (aged $\approx 18-25$ years) are in a transitional period, during which they explore their life directions and options. In this period, they often feel "in-between" adolescence and adulthood and, thus, experience insecurity and anxiety regarding their future (Arnett, 2000; Salmela-Aro et al., 2007). Exploring possibilities, setting and adjusting goals, and making decisions and commitments for adult life are important in this life stage (Shulman \& Nurmi, 2010). Goals play an especially important role, as these direct young people's development and transition from adolescence to adulthood in a period that can involve more planning, goal setting, and evaluation than previous periods (Nurmi et al., 2002). Goals motivate young people to develop strategies, identify opportunities, and explore their environment and themselves (Bandura, 1991; Lent, 2013). In the career context, goals stimulate plans and drive actions for achieving desired occupational outcomes, they influence choices and persistence in higher education (Lent et al., 2010), and contribute to young people finding satisfactory work and being more successful (Nurmi et al., 2002).

Emerging adults must choose their future education and occupation paths as part of their personal goal setting (Arnett, 2000; Salmela-aro et al., 2007). However, goals have a dynamic structure that is continuously (consciously and unconsciously) being appraised, monitored, and reconstructed to meet contextual realities (Bandura, 2001; Carver \& Scheier, 2000; Shulman \& Nurmi, 2010). When goals are appraised, there will inevitably be a difference or a gap between the person's set goal or standard and performance; these are labelled goal-performance discrepancies (Bandura, 2001: Carver \& Scheier, 2000; Lord et al., 2010). In the career development context, Creed and Hood (2015; p.309) defined career goal discrepancies as "the perceived gap between the individual's set career goal (future self or situation) and their career goal progress (current self or situation)”. 
Goal discrepancies are positive if performance or progress exceeds goals or standards, and negative if performance or progress falls short of goals or standards (Carver \& Scheier, 1998; Creed \& Hood, 2015; Lord et al., 2010). According to Carver and Scheier's (1990; 1998) control theory, these different appraisals of performance/progress compared to the set goal/standard have different consequences for affect and the self-regulation process. However, control theory focuses more on negative feedback loops and negative goal discrepancy reduction, which has resulted in more research on self-regulatory responses to negative discrepancy. The consequences of negative discrepancy tend to be unpleasant and noticeable, so individuals are more eager to find solutions to these problems (Carver, 2003).

Ilies and Judge (2005) argued that while control theory provided an adequate mechanism for understanding the consequences of negative goal discrepancies, it is less useful in explaining the affective and self-regulatory consequences of positive goal discrepancies. These authors point to Bandura's (1997) social cognitive theory and Locke and Latham's (1990) goal setting theory as more relevant to understanding positive goal discrepancies. When faced with a positive goal discrepancy, rather than necessarily reducing effort or coasting as control theory predicts, social cognitive and goal setting theories predict that standards and goals are upwardly revised, "creating motivating discrepancies to be mastered" (Bandura, 1997, p. 131). Ilies and Judge noted that, in addition to different underlying theoretical mechanisms, there were different boundary conditions for the positive discrepancy-outcome relationship (e.g., goal difficulty) compared to the negative discrepancy-outcome relationship (e.g., self-efficacy). However, positive discrepancy has largely been overlooked, with most focus given to understanding negative discrepancies (Carver, 2003). Understanding positive discrepancies is important, especially in contexts such as career development, where optimising and developing individual potential is of interest. 
Research to date on career goal discrepancy has focused on the role of negative discrepancies in the career development process, by experimental (Anderson \& Mounts, 2012) and survey methods (Creed et al., 2015; Creed et al., 2017; Hu, Creed, et al., 2017; Hu et al., 2018b). Greater negative career goal-progress discrepancy was related to lower perceived employability (cognitive response; Creed et al., 2017) and higher career-related distress (affective response; Creed et al., 2015; Hu et al., 2018a; Sheppard et al., 2019). Career distress, in turn, was correlated positively with career goal disengagement ( $\mathrm{Hu}, \mathrm{Hood}$, et al., 2017) and revision (Hu, Creed, et al., 2017), identity defence, and exploration (behavioural responses; Anderson \& Mounts, 2012; Sheppard et al., 2019).

In general, positive goal discrepancy research is limited and mostly conducted in laboratory settings (e.g., Ilies \& Judge, 2005; Scherbaum \& Vancouver, 2010) or with specific task performance, such as arithmetic calculations (Donovan \& Hafsteinsson, 2006) and verbal tasks (Tolli \& Schmidt, 2008). Other research has occurred in sporting (e.g., Donovan \& Williams, 2003; Williams et al., 2000) and classroom contexts (Donovan, 2009). No research has examined positive career goal discrepancies. The one existing career goalprogress discrepancy scale (Creed \& Hood, 2015) measures negative discrepancies only. The important differences, both in the underlying mechanisms and boundary conditions, between negative and positive goal discrepancies (Ilies \& Judge, 2005) indicate that positive and negative discrepancies are not polar opposites. Therefore, it is not adequate to simply use a negative goal discrepancy scale to measure positive career goal discrepancy; a new scale is needed. We addressed this gap by developing a valid and reliable positive career goalprogress discrepancy scale, which has the potential to stimulate research in this area.

\section{Career Goal-Progress Discrepancies}

In the career context, Creed and Hood (2015) identified four essential negative discrepancy domains: (a) achievement discrepancy, the appraisal that current achievement is 
inadequate to achieve the future career goal; (b) ability discrepancy, the perception that personal skills and abilities are inadequate to achieve the desired goal; (c) effort discrepancy, the gap between previous effort and that required to achieve the career goal; and (e) standard discrepancy, which is the perception that the career goal is too high.

Creed and Hood (2015) used self-standards only as the comparator for appraisal of career goal performance or progress. According to social-cognitive and control theories (Bandura, 1991; Carver \& Scheier, 1990), people also are likely to compare their goal progress with the performance and expectations of others. For example, students compare their study performance to that of their peers (Unsworth et al., 2016). Thus, the proposed positive discrepancy scale items referenced both internal (i.e., self) and external (social/other) comparators to better capture emerging adult's appraisals of positive discrepancies.

In summary, the limited research to date has focused exclusively on negative career goal-progress discrepancies. There is evidence of different affective and self-regulatory consequences, underlying mechanisms, and boundary conditions for positive goal discrepancies, suggesting these discrepancies are not polar opposites. Positive career goalprogress discrepancies result from appraisals that career-related progress exceeds that needed to meet the desired career goal, which is more aligned with motivational discrepancy production and mastery than with discrepancy reduction (see Ilies \& Judge, 2005). Last, appraisals are made between current progress status and internal (e.g., past performance and personal goals) and external comparators (e.g., expectations of peers and significant others).

\section{Previous Measures of Career Goal Discrepancies}

Wang and Heppner (2002) developed the 32-item Living up to Parental Expectations Inventory, which measures discrepancies between perceived self-performance and perceived parental expectations in personal maturity, academic achievement (including career), and dating relationships. Significant others (i.e., parents) are used as the comparators to identify 
discrepancies. Participants rate perceived parental expectations (e.g., "How strongly do you currently perceive this expectation from your parents?") and self-perceived performance (e.g., "To what extent do you currently perform in this manner?") items using a 6-point scale, where lower scores indicate lower expectations/performance. The total score is obtained by subtracting the perceived parental expectation score from the perceived self-performance score. This is expressed as an absolute difference (not as negative or positive scores), with higher absolute scores indicating higher levels of living up to parental expectations. Although no discrepancy direction is identified, Wang and Heppner found higher expectation scores than performance scores on all subscales, indicating negative rather than positive discrepancies were measured. They provided support for reliability and validity.

Patton and Creed (2007) examined occupational discrepancies by comparing adolescents' occupational aspirations (i.e., jobs most desired) with their realistic occupational expectations (i.e., jobs expected to get). Occupational aspirations and expectations were then classified according to Holland's (1997) RIASEC coding system and characterised as either discrepant, when aspiration and expectation codes differed, or non-discrepant, when participants reported the same aspiration and expected occupational code. Thus, this measure used self or personal standards as the comparator to identify discrepancies. No discrepancy direction was identified in this study as the codes were nominal only.

In their experimental study, Anderson and Mounts (2012) measured occupational identity discrepancy as incongruence between the identity ideal and identity self-perception. At the pre-experimental session, participants were asked to identify their occupational identity standard using the single item, "Please write the name of the occupation you are most interested in", and before the feedback session were required to respond to a career aptitude survey as the experiment cover story. Participants were then given self-discrepant feedback by being told that they were not well suited to their occupational choice based on their 
responses to the aptitude survey. They then generated a post-manipulation identity standard using the same single item and participants were categorised as changed or not changed from pre-manipulation. Being nominal, this measure did not indicate the direction of discrepancy.

To address the lack of a psychometrically sound scale to measure career goal discrepancy, Creed and Hood (2015) devised a 12-item unidimensional scale that covered four domains (achievement, ability, effort, and standard discrepancy; 3 items each; 6-point response format: strongly disagree to strongly agree). All items are worded as negative discrepancies; for example, "My plans are not working out to get the career I really want" (achievement discrepancy). The scale has good reliability $(\alpha=.95)$ and initial support for validity by finding an expected positive association with career distress and a negative association with career goal commitment. However, the scale only measures negative career goal discrepancies and only uses the self as the comparator.

Unsworth et al. (2016) devised a scale to measure perceived discrepancies between nursing students' current performance and that of peers, more advanced students, and qualified or professional nurses. The "discover discrepancy" tool provided scenarios and nine performance criteria as common elements of nursing performance. Students rated $(5 \mathrm{~cm}$ visual analogue scale, $0=$ novice to $5=$ expert ) their current performance and that of their peers, a final-year student, and a newly qualified staff nurse on each criterion. The scale has the potential to identify both positive (performance better than comparators) and negative discrepancies (performance below comparators), although Unsworth et al. treated these as opposites on the same continuum and focused only on the negative discrepancies. The scale's use is limited also as it specifically focuses on performance and knowledge discrepancies in a single career, nursing, and has no published evidence of reliability and validity.

In conclusion, limitations of the different existing measures of career goal discrepancy include that they do not enable measurement of positive goal discrepancies as a distinct 
construct to negative goal discrepancies, only assess the gap between self-set goals and current progress, are situation-specific, or lack psychometric evidence. Consequently, we aimed to develop a psychometrically sound measure of positive career goal discrepancies.

\section{Current Study}

The study consisted of three stages, in line with classic scale development approaches (DeVellis, 2012). In the first stage, we generated items to capture the positive career goal discrepancy construct based on a literature review, reference to earlier scales, and by conducting a series of focus groups with emerging adults. We assessed content validity by having experts rate the suitability of the items, instructions, and response options (Beaton et al., 2000; DeVellis, 2012). In the second stage, we conducted exploratory factor analyses (EFA) to reduce the number of items and assess the scale structure. Divergent and incremental validity checks were conducted to establish that the scale assessed a distinct construct, and explained additional variance in related career outcomes, to negative career goal discrepancy. Using a second sample, we then conducted confirmatory factor analyses (CFA) to test the identified factor structure. In the last stage, we assessed the construct validity by correlating scores on the scale with those of constructs from the nomological net.

The study was conducted in Indonesia with $1^{\text {st }}$-year students from multiple private and public universities. Much of the existing research in career goal discrepancy has been conducted in Western individualist cultures (e.g., Anderson \& Mounts, 2012, Creed \& Hood, 2015). Little is known about career goal discrepancies in non-Western societies, where there are different contextual factors, such as the strong influence of parents and significant others that operate in collectivist cultures (Fouad et al., 2008). In a more strongly collectivist culture such as Indonesia, parental career expectations and career congruence with parents need to be considered in the career decision-making process (Sawitri et al., 2013). Thus, in line with a 
social cognitive approach, external comparators (e.g., parents and peers) become important factors in career goal-progress appraisals and discrepancies.

\section{Method}

\section{Stage 1: Item Development}

The aim here was to generate sufficient items to adequately capture the positive career goal discrepancy construct. We followed Vogt et al.'s (2004) steps in generating the items: review the relevant literature, refine definitions of the key construct/s, conduct focus groups with members of the target population, and use this information to develop a broad pool of items. Based on the literature review and examination of previous career goal discrepancy measures, we identified four potential domains of positive career goal discrepancies that aligned with those previously identified by Creed and Hood (2015) for negative careerprogress discrepancy: achievement (current achievement is more than required to achieve the future career goals), ability (the individual has more personal skills and abilities than required to achieve the desired goals), effort (effort expended to date is more than required to achieve the career goals), and standard discrepancies (the current standard is likely to be surpassed and higher career goals potentially could be set).

Four focus groups were held with $1^{\text {st }}$-year students $(N=26 ; 50 \%$ women; aged $18-20$ years) from private and state universities. Participants were asked to reflect upon and share their own career goals, how they evaluated their career progress, what they drew upon to identify when they were on track or ahead of meeting their goals (i.e., how they defined positive goal discrepancies), what aspects (i.e., domains) they considered when evaluating this progress, and with whom or what they compared their progress. The information from these groups provided corroboration for the definition and domains initially identified. In addition, participants indicated that they compared their career progress to past performance, future goals, parents' expectations, and peers when appraising career discrepancies. 
We generated 48 initial items, approximately 12 for each domain (achievement, ability, standard, and effort) that represented a mix of comparators (past performance, future goals, parents' expectations, and peer comparison). Independent reviewers $(N=7)$ with expertise in scale development and/or career research evaluated each item's suitability $(1=$ not at all suitable to $6=$ very suitable) and commented on item clarity and readability. Based on expert comments and ratings, we deleted 6 items with low ratings $(<5)$ and 10 that were considered less relevant, overlapping, or ambiguous, and revised 9 items to enhance readability. This left 32 items (mean expert ratings $>5$ ). As we were aiming to devise a scale suitable for research purposes of from 12 to 16 items (i.e., 3-4 items per domain with a range of comparators represented) that would not place undue demand on respondents, 32 initial items (approximately twice the final desired number) were sufficient (Hinkin, 1998).

The 32 items were generated in English to suit a broader research use, but, as the study was conducted in Indonesia, we applied the translation-back-translation procedure (Beaton et al., 2000) to convert the items to Bahasa, the main Indonesian language. The first author, whose native language is Bahasa, but who also is fluent in English, translated the items into Bahasa. Five independent Indonesian psychology academics, who also were proficient in English, reviewed and commented on the translated version. Finally, the Bahasa version was translated back into English by another two independent bilingual colleagues, who had not viewed the original English version. The authors then compared the original and back-translation versions and adjusted where needed. As a final check, the Bahasa items were piloted with five Indonesian emerging adults to ensure that the instructions, items, and response format were easy to read and understand. No revisions were required at this stage.

\section{Stage 2: Factor Analysis}

Our aims in this stage were to reduce the number of items and assess the structure of the scale using EFA, check divergent and incremental validity compared to a measure of 
negative career goal-progress discrepancy, confirm the factor structure by using CFA, and provide initial evidence of construct validity by testing expected associations with constructs drawn from the nomological net (career satisfaction and optimism).

\section{Participants}

We received responses from $5121^{\text {st }}$-year students recruited from 7 public and 6 private universities in Java and Sumatra, Indonesia. We discarded 14 cases as they failed attention check items, used patterned responses (e.g., all 1s), or did not complete main parts of the questionnaire. This left 498 participants, who were randomly split into two subsamples (random split function in SPSS V26). Sample A $(N=244)$ was used for item reduction, EFA, and divergent and incremental validity checks with negative career goal discrepancy, and Sample B $(N=254)$ was retained as a hold-out for CFA and to assess construct validity (Byrne, 2010). Sample sizes were sufficient for factor analysis with at least moderate communalities and three items per factor (Fabrigar \& Wegener, 2012).

Sample A comprised 65\% women (5\% did not report gender), whose mean age was 18.7 years $(S D=1.2 ; 5 \%$ missing), evenly split across private $(52 \%)$ and public $(48 \%)$ universities (5\% missing). Participants were enrolled in a range of study programs, including psychology, social sciences, medicine, education, engineering, and computer science. Mean reported GPA was $3.2(S D=0.5$, range $1-4$, higher GPA $=$ better achievement; $6 \%$ missing $)$. For socio-economic situation, $2 \%$ reported it was Much better than others, $16 \%$ as $\mathrm{A}$ little better, $41 \%$ as About the same, $26 \%$ as Alttle worse, and 10\% as Much worse (5\% missing). Sample B comprised $68 \%$ women ( $6 \%$ missing), whose mean age was 18.7 years $(S D=0.8$; $6 \%$ missing), with $48 \%$ and $47 \%$ attending public and private universities, respectively ( $6 \%$ missing). The range of study programs was similar to Sample A. Mean GPA was 3.3 ( $S D=$ $0.4 ; 11 \%$ missing). For socio-economic situation, the percentages were $1 \%, 16 \%, 52 \%, 21 \%$, and $6 \%$, respectively $(6 \%$ missing). 
We compared Samples A and B to test if there were between-group differences on gender, $\chi^{2}(1)=0.71, p=.40$; age, $t(469)=0.52, p=.60 ;$ GPA, $t(438)=1.52, p=.13$; university, $\chi^{2}(1)=1.06, p=.30$; study major, $\chi^{2}(11)=7.34, p=.77$; and social-economic situation, $\chi^{2}(4)=9.25, p=.06$, and found none, suggesting no bias as a result of the split.

\section{Materials}

The 32 positive career goal discrepancy items developed in Stage 1 were included in a questionnaire with demographic questions and scales to assess negative career goal discrepancy (for divergent and incremental validity), career satisfaction, and career optimism (for construct validity), which were drawn from the nomological net of career goal-progress discrepancy. We expected positive career goal discrepancy to be related negatively to negative career goal discrepancy, and as previous studies found positive relationships between managing goal progress and satisfaction (Locke \& Latham, 2006) and having a positive view of the future (Ilies \& Judge, 2005), we expected positive career goal-progress discrepancy to be related positively to career satisfaction and optimism.

Negative career goal discrepancy. We used the 12-item Career Goal Discrepancy Scale (Creed \& Hood, 2015), which assesses perceived shortfall between the individual's career progress and career goals. An example item is, "My plans are not working out to get the career I really want". The authors reported excellent internal reliability $(\alpha=.95)$ and supported validity by finding a negative correlation with career goal commitment and a positive correlation with career distress. Cronbach's alpha with the current sample was .89.

Career satisfaction. We used the unidimensional, 5-item Career Satisfaction Scale (Greenhaus et al., 1990), which evaluates individuals' subjective career success for meeting career-related goals. An example item is, "I am satisfied with the progress I have made toward meeting my overall career goals". This scale generated high internal reliability across several samples ( $\alpha$ range .88 to .92 ; Spurk et al., 2015), and validity has been supported by 
showing scores are related positively to task and career performance (Zacher, 2015) and negatively to neuroticism (Boudreau et al., 2001). Alpha with the current sample was .91.

Career optimism. We used the 11-item Career Optimism Subscale of the Career Futures Inventory (Rottinghaus et al., 2005), which measures individuals' expectations of positive career outcomes. An example item is, "I get excited when I think about my career." The authors reported high internal reliability $(\alpha=.87)$ and gave evidence for construct validity by finding positive correlations with general optimism, positive affect, and problemsolving ability, and negative correlations with negative affect. Alpha was .83.

\section{Procedure}

The study was approved by the authors' university ethics committee and the ethics committees of the participating universities in Indonesia. Students also gave their informed consent before completing the questionnaire. They were contacted via course convenors who provided a link to an online questionnaire or a paper-based questionnaire for those who preferred this. Participants could enter a prize draw to win one of 100 IDR50.000 ( AUS\$5) vouchers. The study was managed by the first author and a research team in Indonesia.

\section{Results}

\section{Exploratory Factor Analysis (Sample A)}

First, we assessed the 32 positive discrepancy items for skewness and kurtosis and examined the inter-item correlations (identifying those $r \leq .30$ and $r \geq .80$ for possible deletion) but did not delete any based on this. Next, we conducted a series of EFAs (principal axis factoring) to assess the underlying scale structure (Hinkin, 1998). As we expected all factors to be correlated, we selected an oblique rotation (direct oblimin; Fabrigar \& Wegener, 2012). The Kaiser-Meyer-Olkin measure of sampling adequacy (.93) and Bartlett's Test of sphericity $(p<.001)$ indicated that the 32 items were suitable for an EFA.

Various criteria were used to determine the number of factors, including eigenvalues $>1$, scree plot, Velicer's minimum average partial (MAP) test and parallel analysis 
(O’Connor, 2000), a minimum of three items per factor (Costello \& Osborne, 2005), item coefficients $>.40$, and factorial meaningfulness (Hinkin, 1998). In the first EFA, we removed items that were cross-loading $(>.40)$ or did not load substantially on any factor $(<.40$; Hinkin, 1998). We then re-ran the EFA and conducted a parallel analysis and Velicer's MAP test. The EFA result showed three factors with eigenvalues $>1$, and the parallel and MAP tests also identified three factors. Thus, we retained the 3-factor solution (see Table 1).

Factor 1, labelled Achievement and Ability Discrepancy contained six items that assessed appraised positive discrepancies between current abilities and achievements and what was required (e.g., "My achievements exceed those needed for my future career"). Factor 2, with five items, assessed positive discrepancies between set career goals and expectations (e.g., "I am confident that I can achieve a higher career goal than I thought possible before"), and was labelled Standard Discrepancy. Factor 3, with four items, assessed the positive discrepancy between effort expended to date and effort required to achieve the goal (e.g., "I am putting in more effort than needed to achieve my future career goals"); labelled Effort Discrepancy. Total variance explained by the 15 items was $63.2 \%$ (F1= $42.2 \%$, eigenvalue $6.33 ; \mathrm{F} 2=11.5 \%, 1.72 ; \mathrm{F} 3=9.5 \%, 1.43$ ), factor loadings ranged from .46 to .84 , and internal reliabilities (Cronbach's $\alpha$ s) were .90 (full scale), .90 (F1), .83 (F2), and .76 (F3). There were positive correlations between Factors 1 and $2(r=.52, p<.001)$, Factors 1 and $3(r=.51, p<.001)$, and Factors 2 and $3(r=.47, p<.001)$.

\section{Divergent and Incremental Validity Check}

We examined the correlations between the positive and negative career goal discrepancy scales (see Table 2) to assess divergent validity. All correlations were weak and negative or not significant (total score $r=-.21, p<.01$; subscale $r$ s range -.01 to -.24 ), supporting divergent validity. We then used multiple regression to test for incremental validity of the positive discrepancy scale over the negative discrepancy scale when predicting 
career satisfaction and optimism. At Step 1, age, gender, SES, and GPA were not associated with satisfaction or optimism. At Step 2, negative career goal discrepancy had no relationship with satisfaction, $\beta=.07, t(201)=1.15, p=.25, F_{\text {Change }}(1,201)=.26, p=.61$, but accounted for an additional $31 \%$ of variance in optimism, $\beta=-.49, t(201)=-8.83, p<.00, F_{\text {Change }}(1$, $201)=90.52, p<.001$. At Step 3, positive career goal discrepancy accounted for an additional $25 \%$ of the variance in satisfaction, $\beta=51, t(200)=8.18, p<.001, F_{\text {Change }}(1,200)$ $=66.96, p<.001$ (25\% total variance explained), and an additional $11 \%$ in optimism, $\beta=.34$, $t(200)=6.19, p<.00, F_{\text {Change }}(1,200)=38.29, p<.001$ (42\% total variance explained). These results indicate that the Positive Career Goal Discrepancy Scale measures a distinct construct to the negative discrepancy scale (Hunsley \& Meyer, 2003).

\section{Confirmatory Factor Analysis (Sample B)}

We used CFA to confirm the factor structure of the 15-item Positive Career Goal Discrepancy Scale on Sample B. As the EFA output indicated positive correlations among the factors, we followed Canivez's (2016) recommendations and assessed four possible models (a multi-factor model, a 1-factor model, a $2^{\text {nd }}$-order model, and a bifactor model). For Model A, the 3-factor model identified in the EFA, each item was assigned to its respective latent variable and correlations among the latent variables were estimated. Model B, the 1-factor model, assessed if all items could be represented by a unidimensional scale (assigning all items to a single latent variable). Model $\mathrm{C}$, the $2^{\text {nd }}$-order model, assessed if the three factors could be represented by a single, higher-level factor (the three latent variables also assigned to a single latent variable). Last, Model D, the bifactor model, assessed the proportion of common variance explained by a general factor after controlling for the sub-factors (all items assigned to their respective latent variables as well as to a general factor).

We applied CFA (AMOS V26) to assess the four models. The fit statistics used were those recommended by Byrne (2010): $\chi^{2}$ ( $p<.05$ expected), $\chi^{2} / \mathrm{df}$ ratio $(<3: 1$ desired), 
Comparative Fit Index (CFI; > .90), Tucker-Lewis Index (TLI; > .90), Root Means Square Error Approximation (RMSEA; < .08), and Standardized Root Mean Square Residual (SRMR; < 80). Akaike's Information Criterion (AIC) was used to compare models given these models were not nested, with a lower AIC indicating a better fit. The fit statistics for the four models are reported in Table 3.

While the bifactor model had the lowest AIC, all three multi-factor models (i.e., 3factor, $2^{\text {nd }}$-order, and bifactor) generated acceptable fit statistics. To help interpret the bifactor model and to compute model-based statistics, we followed recommendations by Rodriguez et al. (2016) and used the Bifactor Indices Calculator (Dueber, 2017) to calculate relevant bifactor reliability and other coefficients $(\omega, \omega \mathrm{H}$, relative $\omega$, Explained Common Variance [ECV], Percent of Uncontaminated Variance [PUC], and Individual Explained Common Variance [IECV]). See Table 4. Model-based statistics indicate whether positive career goal discrepancy is better considered as a general factor (i.e., better to use at the total scale score level) or is more reliably interpreted at the group factor level (i.e., at the subscale score level).

The Omega $(\omega)$ reliability coefficients were .91 (general factor), .87 (achievement and ability discrepancy), .76 (standard discrepancy), and .78 (effort discrepancy), indicating high reliability for the general factor and good reliability for the specific factors. Omega $H(\omega H)$, or the proportion of variance attributed to a factor, was .81 for the general factor and $.16, .31$, and .23 , respectively, for the specific factors. When $\omega \mathrm{H}$ is high $(>.80)$, a multidimensional construct is better considered at the total score than subscale level (Rodriguez et al., 2016b). Relative $\omega$ (proportion of reliable variance due to a factor) was .89 (general factor) and .18, .40 and .30 (respective subscales). The higher Relative $\omega$ for the general factor indicates that interpretation of the scale is more reliable at the general factor level (i.e., total score level).

The ECV was .66 (general factor) and $.24, .44$, and .38 for the subscales, indicating that the general factor explained a greater proportion of common variance than the specific 
factors; also indicating that the total score would provide a more meaningful measure of positive discrepancy than the subscale scores. For IECV, the contribution of each item to the general factor, six items were relatively high (i.e., > .80; 4 achievement/ability, 1 standard discrepancy, and 1 effort discrepancy item), suggesting that achievement/ability items mainly explained the variance in positive career goal discrepancy (Stucky \& Edelen, 2015).

The PUC also can indicate whether the general or specific factor level is the most relevant to use and report (Rodriguez et al., 2016a), although when PUC values are $<.80$, general ECV values should be considered, with ECV $>.60$ and $\omega \mathrm{H}>.70$ as benchmarks (Reise et al., 2013). PUC in our model was .71, ECV was .66, and $\omega \mathrm{H}$ was .81, supporting interpretation at the general factor level. Thus, based on the pattern of these model-based statistics, we concluded that the scale is best applied at the general or total score level.

\section{Stage 3: Construct Validity (Sample B)}

Construct validity was assessed by testing the correlations between the Positive Career Goal Discrepancy Scale (full scale) and the validity scales (i.e., career satisfaction, optimism, and negative career goal discrepancy; see Table 5). There were strong positive correlations between total positive discrepancy and career satisfaction and optimism, and a weak negative association between the positive and negative career goal discrepancy scores. Further, correlations with age, gender, and SES were negligible ( $r$ range -.03 to .15 ); thus, no marked differences in the way different demographic groups might respond to the scale. In all, these results identified no bias in the scale and provided additional support for validity.

\section{Discussion}

We aimed to develop a psychometrically sound scale to measure positive career goalprogress discrepancies to address an identified gap. The resulting 15 -item self-report scale assesses three domains of positive career goal-progress discrepancy: positive achievement and ability discrepancy, standard discrepancy, and effort discrepancy, with model testing 
indicating the most meaningful interpretation is achieved at the total score level. The study advances theoretical understanding of how positive goal discrepancy is manifested in the career context, especially in emerging adults. It also contributes to the existing career goal discrepancy literature, which has focused primarily on negative discrepancies, and will enable researchers to test hypotheses regarding positive discrepancies.

Based on the career goal discrepancy literature (e.g., Anderson \& Mounts, 2012; Creed \& Hood, 2015), we operationalised positive career goal discrepancies as appraisals that career-related progress exceeds that required to meet the individual's career goal/s. Positive discrepancy differs from negative discrepancy in the theoretical models that best explain the constructs, and there are differences in affective and self-regulatory outcomes and the boundary conditions for the two constructs. Social cognitive (Bandura, 1991) and goal-setting theories (Locke \& Latham, 2006) provide more adequate explanations of the motivational and mastery discrepancy production nature of positive goal discrepancies, while control theory (Carver \& Scheier, 1990) is more relevant to understanding the discrepancy reduction nature of negative discrepancies (Ilies \& Judge, 2005). When career goals have been exceeded, social cognitive theory predicts that individuals will experience positive affect and will engage in upward goal revision and increase their mastery efforts. On the other hand, according to control theory, unmet career goals will lead to negative affect and downward goal revision in order to decrease the discrepancy (Ilies \& Judge, 2005).

We provide empirical evidence that positive and negative goal discrepancies are largely independent constructs and not simply poles on a single continuum. There was negligible shared variance between scores on the new positive career goal discrepancy scale and Creed and Hood's (2015) negative career goal discrepancy scale. Furthermore, the new positive career goal discrepancy scale provided additional predictive power in explaining variance in career optimism and satisfaction to that of negative career goal discrepancy. 
We identified three underlying domains in positive career goal discrepancy, rather than the four previously identified for the negative discrepancy construct (Creed \& Hood, 2015). We did not find evidence for separate achievement and ability discrepancy domains, but found these items loaded on a single underlying ability/achievement discrepancy domain. Potentially, when young adults appraise their progress, they make more global appraisals when making good progress and associated affect is positive but discriminate more among causal factors when all is not well. The explanation is that positive affect broadens attention by encouraging openness to possibilities other than the current goal, while negative affect narrows attention to focus more on specific threats or problems to be solved (Carver, 2003). Scholars need to continue researching and developing theory around the career goal discrepancy construct to ensure all underlying domains are identified.

The bifactor model test indicated the scale was best interpreted at the general factor or total score level. There was excellent internal reliability for this $(\omega=.91)$ and initial construct validity was supported by finding expected positive correlations with career optimism and satisfaction, which were drawn from the nomological net of the positive goal discrepancy construct. Additionally, we found trivial associations between the total score and age, gender, and SES, suggesting little distortion when completed by these different groupings. As most of our sample reported SES as about average, we were unable to test measurement invariance across different SES groups. Future research should examine this.

The Positive Career Goal Discrepancy Scale can be used to examine the role of positive goal discrepancies when considering the career progress of emerging adults. Goal discrepancies trigger affective responses and self-regulatory processes aimed at adjusting career-related goals and/or behaviours (Bandura, 1991; Carver \& Scheier, 2000). To date, the lack of a psychometrically sound measure of positive discrepancy restricted empirical research to theoretical predictions related to negative career goal discrepancies. This new 
measure will enable career researchers to test theoretical propositions regarding positive discrepancies. For example, do individuals who experience a positive career goal discrepancy experience positive affect, such as elation, and then upwardly revise their goals by setting more challenging ones (vis-à-vis discrepancy production; Bandura, 1991)? Do they withdraw effort (vis-à-vis coasting; Carver, 2003). What boundary conditions affect these responses?

This new scale also could be adapted for use in other research areas where positive goal-performance discrepancies are of interest, such as in academic achievement and sports performance. Goal-performance discrepancy research in these contexts has been restricted to experimental manipulation and measurement of discrepancies via differences in self- and other-set performance goals (e.g., ideal test scores or running times; Donovan \& Hafsteinsson, 2006; Ilies \& Judge, 2005; Scherbaum \& Vancouver, 2010; Tolli \& Schmidt, 2008). An adapted scale would enable researchers to investigate how individuals in these contexts respond and change their behaviour and/or goals in response to appraised positive discrepancies using non-experimental and, thus, potentially more realistic research methods.

This newly devised scale will also be useful for academic advisors and counsellors who assist emerging adults to maximise progress towards their career goals. Practitioners can help clients identify how well they are progressing as an incentive to re-evaluate their career goals and consider more challenging ones to help them maintain motivation and effort.

Equally, it might be useful to show those who are feeling overwhelmed by the effort they are directing towards their goals that they are doing more than enough, and they can "coast".

\section{Limitations}

This scale was developed and validated in a sample of university-based young adults from one country. Contextual factors might have affected the construct definition as well as the results. Parents were the comparators on the highest loading items on the achievement/ ability and standard discrepancy factor. Parental expectations are important considerations in 
career development in collectivist cultures such as Indonesia (Sawitri et al., 2013; 2020). On the other hand, in individualist cultures there is more emphasis on personal accomplishment and self-fulfilment (Oyserman et al., 2002), so the self as comparator might be more relevant. Thus, the applicability of this scale needs to be tested in other populations, including those with different cultural backgrounds (e.g., individualist) and with different educational and SES levels (e.g., less well-educated emerging adults, lower SES groups).

Our sample comprised more young women than men, the majority were enrolled in social science courses, and were of higher socio-economic status than emerging adults in general. While we found no strong association between positive career goal discrepancy and these demographic characteristics, future studies with larger samples need to assess invariance across SES and other groupings. While we provided initial evidence of construct validity via expected associations with other related constructs (i.e., career satisfaction and optimism) and of divergent and incremental validity compared to negative career goal discrepancy, future research needs to extend the evidence for validity; for example, by demonstrating that positive discrepancies do not simply reflect trait-based responses. Last, we were not able to assess predictive validity, which is important for all assessment tools, and future studies need to evaluate this. For example, positive career goal discrepancy should predict subsequent self-regulatory responses such as upward goal revision and/or coasting.

\section{Conclusion}

This study contributed by developing and validating the Positive Career Goal Discrepancy Scale, a measure to assess positive career goal discrepancies in emerging adults. This scale assesses discrepancies in achievement and ability, standards, and effort relative to both internal and external comparators. It shows promising psychometric properties and will be a useful addition to the career literature, potentially stimulating research into how young people who are progressing well with their career goals can maintain and increase their 
motivation and optimise their career development. It also will be useful to career practitioners when they come to assist young people with achieving their career promise. 


\section{References}

Anderson, K. L., \& Mounts, N. S. (2012). Searching for the self: An identity control theory approach to triggers of occupational exploration. Journal of Genetic Psychology, 173(1), 90-111. https://doi.org/10.1080/00221325.2011.573027

Arnett, J. J. (2000). Emerging adulthood: A theory of development from the late teens through the twenties. American Psychologist, 55(5), 469-480. https://doi.org/10.1037/0003-066X.55.5.469

Bandura, A. (1991). Social cognitive theory of self-regulation. Organizational Behavior and Human Decision Processes, 50(2), 248-287. http://www.uky.edu/ eushe2/BanduraPubs/Bandura1991OBHDP.pdf

Bandura, A. (2001). Social cognitive theory: an agentic perspective. Annual Review, 52(1), 1-26. https://doi.org/10.1146/annurev.psych.52.1.1

Beaton, D. E., Bombardier, C., Guillemin, F., \& Ferraz, M. B. (2000). Guidelines for the process of cross-cultural adaptation. Spine, 25(24), 3186-3191. https://doi.org/10.1111/cch.12124

Boudreau, J. W., Boswell, W. R., \& Judge, T. A. (2001). Effects of Personality on Executive Career Success in the United States and Europe. Journal of Vocational Behavior, 58(1), 53-81. https://doi.org/10.1006/jvbe.2000.1755

Byrne, B. M. (2010). Structural Equational Modeling with AMOS: Basic Concepts, Applications and Programming (2nd Editio). Routledge Taylor \& Francis Group.

Canivez, G. L. (2016). Bifactor modeling in construct validation of multifactored tests: Implications for understanding multidimensional constructs and test interpretation. In K. Schweizer \& C. DiStefano (Eds.), Principles and methods of test construction: Standards and recent advancements (pp. 247-271). Hogrefe.

Carver, C. S. (2003). Pleasure as a sign you can attend to something else: Placing positive 
feelings within a general model of affect. Cognition and Emotion, 17(2), 241-261.

https://doi.org/10.1080/02699930302294

Carver, C. S., \& Scheier, M. F. (1990). Origins and functions of positive and negative affect: A control-process view. Psychological Review, 97(1), 19-35.

https://doi.org/10.1037//0033-295X.97.1.19

Carver, C. S., \& Scheier, M. F. (2000). On the stucture of behavioral self-regulation. In M. Boekaerts, P. R. Pintrich, \& M. Zeinder (Eds.), Handbook of Self-Regulation (pp. 4184). Academic Press.

Costello, A. B., \& Osborne, J. W. (2005). Best practices in exploratory factor analysis: Four recommendations for getting the most from your analysis. Practical Assessment, Research and Evaluation, 10(7), 1-9. https://doi.org/10.7275/jyj1-4868

Creed, P. A., \& Hood, M. (2015). The development and initial validation of a scale to assess career goal discrepancies. Journal of Career Assessment, 23(2), 308-317. https://doi.org/10.1177/1069072714535175

Creed, P. A., Hood, M., \& Hu, S. (2017). Personal orientation as an antecedent to career stress and employability confidence: The intervening roles of career goal-performance discrepancy and career goal importance. Journal of Vocational Behavior, 99, 79-92. https://doi.org/10.1016/j.jvb.2016.12.007

Creed, P. A., Wamelink, T., \& Hu, S. (2015). Antecedents and consequences to perceived career goal-progress discrepancies. Journal of Vocational Behavior, 87, 43-53. https://doi.org/10.1016/j.jvb.2014.12.001

DeVellis, R. F. (2012). Scale development: theory and applications (3rd ed.). SAGE Publications, Inc.

Donovan, J. J. (2009). Antecedents of discrepancy production in an achievement setting. Journal of Managerial Issues, 21(3), 402-420. www.jstor.org/stable/40604657Copy 
Donovan, J. J., \& Hafsteinsson, L. G. (2006). The impact of goal-performance discrepancies, self-efficacy, and goal orientation on upward goal revision. Journal of Applied Social Psychology, 36(4), 1046-1069. https://doi.org/10.1111/j.0021-9029.2006.00054.x

Donovan, J. J., \& Williams, K. J. (2003). Missing the mark: Effects of time and causal attributions on goal revision in response to goal-performance discrepancies. Journal of Applied Psychology, 88(3), 379-390. https://doi.org/10.1037/0021-9010.88.3.379

Dueber, D. M. (2017). Bifactor indices calculator: A Microsoft excel-based tool to calculate various indices relevant to bifactor CFA models.

https://doi.org/doi:10.13023/edp.tool.01

Fabrigar, L. R., \& Wegener, D. T. (2012). Exploratory Factor Analysis. Oxford University Press, Inc.

Fouad, N. A., Kantamneni, N., Smothers, M. K., Chen, Y. L., Fitzpatrick, M., \& Terry, S. (2008). Asian American career development: A qualitative analysis. Journal of Vocational Behavior, 72, 43-59. https://doi.org/10.1016/j.jvb.2007.10.002

Greenhaus, J. H., Parasuraman, S., \& Wormley, W. (1990). Effects of race on organizational experiences, job performance evaluations, and career outcomes. Academy of Management Journal, 33(1), 64-86. https://doi.org/10.2307/256352

Hinkin, T. R. (1998). A Brief Tutorial on the Development of Measure for Use in Survey Questionnaires. Organizational Research Methods, 1(1), 104-121. https://doi.org/10.1177/109442819800100106

Hu, S., Creed, P. A., \& Hood, M. (2017). Career goal revision in response to negative feedback: Testing a longitudinal cross-lagged model. Journal of Counseling Psychology, 64(3), 335-345. https://doi.org/10.1037/cou0000193

Hu, S., Hood, M., \& Creed, P. A. (2017). Negative career feedback and career goal disengagement in young adults: The moderating role of mind-set about work. Journal of 
Vocational Behavior, 102, 63-71. https://doi.org/10.1016/j.jvb.2017.07.006

Hu, S., Hood, M., \& Creed, P. A. (2018a). Career goal importance as a moderator in the relationship between career feedback and career-related stress. Journal of Career Development, 45(1), 3-18. https://doi.org/10.1177/0894845316667847

Hu, S., Hood, M., \& Creed, P. A. (2018b). Within-person relationship between career goal feedback and career-related stress: A weekly survey study. Journal of Counseling Psychology, 65(6), 681-689. https://doi.org/10.1037/cou0000282

Hunsley, J., \& Meyer, G. J. (2003). The Incremental Validity of Psychological Testing and Assessment: Conceptual, Methodological, and Statistical Issues. Psychological Assessment, 15(4), 446-455. https://doi.org/10.1037/1040-3590.15.4.446

Ilies, R., \& Judge, T. A. (2005). Goal regulation across time: The effects of feedback and affect. Journal of Applied Psychology, 90(3), 453-467. https://doi.org/10.1037/00219010.90 .3 .453

Lent, R. W., Sheu, H. Bin, Gloster, C. S., \& Wilkins, G. (2010). Longitudinal test of the social cognitive model of choice in engineering students at historically black universities. Journal of Vocational Behavior, 76(3), 387-394.

https://doi.org/10.1016/j.jvb.2009.09.002

Locke, E. A., \& Latham, G. P. (1990). A theory of goal setting and task performance. Prentice-Hall, Inc.

Locke, E. A., \& Latham, G. P. (2006). New directions in goal-setting theory. Association for Psychological Science, 15(5), 265-268. https://doi.org/10.1111/j.14678721.2006.00449.x

Lord, R., Diefendorff, J. M., Schmidt, A. M., \& Hall, R. A. (2010). Self-regulation at work. Annual Review, 61, 543-568. https://doi.org/10.1146/annurev.psych.093008.100314 Nurmi, J. E., Salmela-Aro, K., \& Koivisto, P. (2002). Goal importance and related 
achievement beliefs and emotions during the transition from vocational school to work: Antecedents and consequences. Journal of Vocational Behavior, 60(2), 241-261. https://doi.org/10.1006/jvbe.2001.1866

O'Connor, B. P. (2000). SPSS and SAS programs for determining the number of components using parallel analysis and Velicer's MAP test. Behavior Research Methods, Instruments, and Computers, 32(3), 396-402. https://doi.org/10.3758/bf03200807

Oyserman, D., Coon, H. M., \& Kemmelmeier, M. (2002). Rethinking Individualism and Collectivism : Evaluation of Theoretical Assumptions and Meta-Analyses. Psychological Bulletin, 128(1), 3-72. https://doi.org/10.1037//0033-2909.128.1.3

Patton, W., \& Creed, P. A. (2007). The relationship between career variables and occupational aspirations and expectations for Australian high school adolescents. Journal of Career Development, 34(2), 127-148. https://doi.org/10.1177/0894845307307471

Reise, S. P., Scheines, R., Widaman, K. F., \& Haviland, M. G. (2013). Multidimensionality and Structural Coefficient Bias in Structural Equation Modeling : A Bifactor Perspective. Educational and Psychological Measurement, 73(1), 5-26. https://doi.org/10.1177/0013164412449831

Rodriguez, A., Reise, S. P., \& Haviland, M. G. (2016a). Applying Bifactor Statistical Indices in the Evaluation of Psychological Measures. Journal of Personality Assessment, 98(3), 223-237. https://doi.org/10.1080/00223891.2015.1089249

Rodriguez, A., Reise, S. P., \& Haviland, M. G. (2016b). Evaluating bifactor models: Calculating and interpreting statistical indices. Psychological Methods, 21(2), 137-150. https://doi.org/10.1037/met0000045

Rottinghaus, P. J., Day, S. X., \& Borgen, F. H. (2005). The career futures inventory: A measure of career-related adaptability and optimism. Journal of Career Assessment, 
13(1), 3-24. https://doi.org/10.1177/1069072704270271

Salmela-aro, K., Aunola, K., \& Nurmi, J. E. (2007). Personal goals during emerging adulthood: A 10-year follow up. Journal of Adolescent Research, 22(6), 690-715. https://doi.org/10.1177/0743558407303978

Sawitri, D. R., Creed, P. A., \& Perdhana, M. S. (2020). The Discrepancies Between Individual-Set and Parent-Set Career Goals Scale: Development and Initial Validation. Journal of Career Development, 1-16. https://doi.org/10.1177/0894845320901795

Sawitri, D. R., Creed, P. A., \& Zimmer-Gembeck, M. J. (2013). The adolescent-parent career congruence scale: Development and initial validation. Journal of Career Assessment, 21, 210-226. https://doi.org/10.1177/1069072712466723

Scherbaum, C. A., \& Vancouver, J. B. (2010). If we produce discrepancies, then how? Testing a computational process model of positive goal revision. Journal of Applied Social Psychology, 40(9), 2201-2231. https://doi.org/10.1111/j.1559-1816.2010.00656.x

Sheppard, S., Hood, M., \& Creed, P. A. (2019). An identity control theory approach to managing career identity in emerging adults. Emerging Adulthood, 1-6. https://doi.org/10.1177/2167696819830484

Shulman, S., \& Nurmi, J. E. (2010). Dynamics of goal pursuit and personality make-up among emerging adults: typology, change over time, and adaptation. New Directions for Child and Adolescent Development, 130, 57-70. https://doi.org/10.1002/cd

Spurk, D., Abele, A. E., \& Volmer, J. (2015). The Career Satisfaction Scale in context: A test for measurement invariance across four occupational groups. Journal of Career Assessment, 23(2), 191-209. https://doi.org/10.1177/1069072714535019

Stucky, B. D., \& Edelen, M. O. (2015). Using hierarchical IRT models to create unidimensional measures from multidimensional data. In S. P. Reise \& D. A. Revicki (Eds.), Handbook of item response theory modeling: Applications to typical 
performance assessment (pp. 183-206). Routledge. https://ebookcentral-proquestcom.libraryproxy.griffith.edu.au

Tolli, A. P., \& Schmidt, A. M. (2008). The role of feedback, causal attributions, and selfefficacy in goal revision. Journal of Applied Psychology, 93(3), 692-701. https://doi.org/10.1037/0021-9010.93.3.692

Unsworth, J., Melling, A., Tuffnell, C., \& Allan, J. (2016). Improving performance amongst nursing students through the discovery of discrepancies during simulation. Nurse Education in Practice, 16(1), 47-53. https://doi.org/10.1016/j.nepr.2015.07.003

Vogt, D. S., King, D. W., \& King, L. A. (2004). Focus groups in psychological assessment: Enhancing content validity by consulting members of the target population. Psychological Assessment, 16(3), 231-243. https://doi.org/10.1037/1040-3590.16.3.231

Wang, L.-F., \& Heppner, P. P. (2002). Assessing the impact of parental expectations and psychological distress on Taiwanese college students. The Counseling Psychologist, 30(4), 582-608. https://doi.org/10.1177/00100002030004006

Williams, K. J., Donovan, J. J., \& Dodge, T. L. (2000). Self-regulation of performance: goal establishment and goal revision processes in athletes. Human Performance, 13(2), 159180. https://doi.org/10.1207/s15327043hup1302_3

Zacher, H. (2015). Daily manifestations of career adaptability: Relationships with job and career outcomes. Journal of Vocational Behavior, 91, 76-86.

https://doi.org/10.1016/j.jvb.2015.09.003 
Table 1

Items and Factors Loadings for Positive Career Goal Discrepancy Scale $(N=244)$.

Items

Ability and achievement discrepancy $(\alpha=.90)$

1. What I have achieved to date in my career has exceeded my parent's expectations.

2. My parents are impressed by the high level of my career-related abilities.

3. My career-related skills and abilities have developed better than my parents expected.

4. Compared to my peers, I have more of what it takes to reach the career I want.

5. My achievements exceed those needed for my future career.

6. I have more skills than needed to achieve my future career goals.

\section{Standard discrepancy $(\alpha=.83)$}

7. I have higher career goals for myself than my parents have for me.

8. I have set my sights on a career that goes beyond my parents' expectations.

9. I have set my career goals higher as I now think I can do better than I thought previously.

10. I am confident that I can achieve a higher career goal than I thought possible before.

11. I am sure that I will surpass the goals I set for my chosen career.

Effort discrepancy $(\alpha=.76)$

12. I am putting in more effort than needed to achieve my future career goals.

13. Because of my efforts toward my career, I am now making better progress than I did previously.

14. I am putting in more effort to achieve my career goals than I did in the past.

15. I am working harder at achieving my career than my friends.

\section{Eigenvalues}

$\%$ of Variance explained

F1 F2 F3

$\begin{array}{lll}\mathbf{. 8 4} & .01 & -.11 \\ \mathbf{. 7 7} & .02 & -.04 \\ . \mathbf{7 3} & .00 & .04 \\ \mathbf{. 7 3} & .09 & .05 \\ \mathbf{. 7 2} & .02 & .14 \\ \mathbf{. 6 7} & .05 & .06\end{array}$

$\begin{array}{ccc}.03 & \mathbf{. 8 0} & -.17 \\ .14 & \mathbf{. 6 8} & -.08 \\ .05 & \mathbf{. 6 2} & .13 \\ -.09 & \mathbf{. 6 0} & .26 \\ .03 & \mathbf{. 5 8} & .18\end{array}$

\begin{tabular}{ccc}
.08 & .08 & $\mathbf{. 7 0}$ \\
.08 & -.01 & $\mathbf{. 6 8}$ \\
-.06 & .10 & $\mathbf{. 6 1}$ \\
.34 & -.05 & $\mathbf{. 4 6}$ \\
\hline 6.33 & 1.72 & 1.43 \\
$42.2 \%$ & $11.5 \%$ & $9.5 \%$
\end{tabular}

Note: Total variance explained $=63.2 \%$. Full-scale $\alpha=.90$. Main loadings are highlighted in bold. The Bahasa Indonesia version of the scale is available from the first author. 
Table 2

Summary Statistics: Sample A $(N=244)$

\begin{tabular}{|c|c|c|c|c|c|c|c|c|c|c|}
\hline Variables & $M$ & $S D$ & 1 & 2 & 3 & 4 & 5 & 6 & 7 & 8 \\
\hline 1. Positive career goal discrepancy (Total) & 66.79 & 9.59 & & & & & & & & \\
\hline Positive achievement/ability discrepancy & 23.62 & 5.17 & $.87 * * *$ & & & & & & & \\
\hline Positive standard discrepancy & 23.82 & 3.83 & $.81 * * *$ & $.51 * * *$ & & & & & & \\
\hline 4. Positive effort discrepancy & 19.34 & 2.61 & $.72 * * *$ & $.50 * * *$ & $.49 * * *$ & & & & & \\
\hline 5. Negative career goal discrepancy (Total) & 40.64 & 10.11 & $-.21 * *$ & $-.16^{* *}$ & $-.17 * *$ & $-.17 * *$ & & & & \\
\hline 6. Negative achievement discrepancy & 9.74 & 3.02 & $-.24 * * *$ & $-.21 * *$ & $-.19 * *$ & $-.17 *$ & $.83 * * *$ & & & \\
\hline Negative effort discrepancy & 10.29 & 2.91 & $-.21 * *$ & $-.17^{*}$ & $-.19 * *$ & $-.16^{*}$ & $.90 * * *$ & $.67 * * *$ & & \\
\hline Negative standard discrepancy & 10.14 & 3.32 & $-.20 * *$ & $-.17 * *$ & $-.15 *$ & $-.16^{*}$ & $.91 * * *$ & $.62 * * *$ & $.77 * * *$ & \\
\hline 9. Negative ability discrepancy & 10.47 & 2.35 & -.04 & -.01 & -.03 & -.08 & $.84 * * *$ & $.58 * * *$ & $.69 * * *$ & $.73 * * *$ \\
\hline
\end{tabular}

Note. $* p<.05, * * p<.01, * * * p<.001$ 
Table 3

Fit Statistics for CFA Models $(N=254)$.

\begin{tabular}{lccccccccc}
\hline Models & $\chi^{2}$ & $d f$ & $\chi^{2} / d f$ & TLI & CFI & RMSEA & $90 \%$ CI & SRMR & AIC \\
\hline Model A: 3-factor & 201.88 & 85 & 2.38 & .91 & .92 & .07 & {$[.06, .09]$} & .06 & 271.88 \\
Model B: 1-factor & 300.71 & 88 & 3.42 & .83 & .86 & .10 & {$[.09, .12]$} & .06 & 364.72 \\
Model C: 2 & & & & & & & & \\
& & & & & & & & & \\
Morder & 201.88 & 85 & 2.38 & .91 & .92 & .07 & {$[.06, .09]$} & .06 & 271.88 \\
Model D: Bifactor & 164.37 & 74 & 2.22 & .92 & .94 & .07 & {$[.06, .08]$} & .05 & 256.37
\end{tabular}

Note: $\mathrm{AIC}=$ Akaike Information Criterion; $\mathrm{CFI}=$ Comparative Fit Index; CI = Confidence Intervals; $\mathrm{df}=$ Degrees

of Freedom; RMSEA = Root Mean Square Error of Approximation; SRMR = Standardized Root Mean Square

Residual; TLI = Tucker-Lewis Index. 
Table 4

Confirmatory Factor Analysis Standardised Factor Loading, IECV, ECV and Model-Based Reliability Estimates According to a Bifactor Model $(N=254)$.

\begin{tabular}{|c|c|c|c|c|c|}
\hline \multirow[t]{2}{*}{ Items } & \multirow[t]{2}{*}{ IECV } & \multicolumn{4}{|c|}{ Standardised Factor Loading } \\
\hline & & General & Factor 1 & Factor 2 & Factor 3 \\
\hline \multicolumn{6}{|c|}{ Ability and achievement discrepancy } \\
\hline Item 1 & .91 & .64 & .20 & & \\
\hline Item 2 & .34 & .51 & .71 & & \\
\hline Item 3 & .74 & .63 & .38 & & \\
\hline Item 4 & .98 & .71 & .10 & & \\
\hline Item 5 & .98 & .71 & .11 & & \\
\hline Item 6 & .82 & .64 & .30 & & \\
\hline \multicolumn{6}{|l|}{ Standard discrepancy } \\
\hline Item 7 & .50 & .51 & & .51 & \\
\hline Item 8 & .36 & .50 & & .68 & \\
\hline Item 9 & .77 & .60 & & .33 & \\
\hline Item 10 & .68 & .35 & & .25 & \\
\hline Item 11 & .83 & .40 & & .18 & \\
\hline \multicolumn{6}{|l|}{ Effort discrepancy } \\
\hline Item 12 & .30 & .48 & & & .73 \\
\hline Item 13 & .70 & .51 & & & .33 \\
\hline Item 14 & .73 & .56 & & & .34 \\
\hline Item 15 & .99 & .66 & & & .03 \\
\hline $\mathrm{ECV}$ & & .66 & .24 & .44 & .38 \\
\hline$\omega$ & & .91 & .87 & .76 & .78 \\
\hline$\omega \mathrm{H}$ & & .81 & .16 & .31 & .23 \\
\hline Relative $\omega$ & & .89 & .18 & .40 & .30 \\
\hline
\end{tabular}


Table 5

Summary Statistics: Sample B $(N=254)$

\begin{tabular}{|c|c|c|c|c|c|c|c|c|}
\hline Variables & $M$ & $S D$ & 1 & 2 & 3 & 4 & 5 & 6 \\
\hline 1. Full scale: Positive career goal discrepancy & 66.46 & 9.04 & & & & & & \\
\hline 2. Career satisfaction & 21.36 & 4.54 & $.61 * * *$ & & & & & \\
\hline 3. Career optimism & 49.56 & 7.34 & $.50 * * *$ & $.32 * * *$ & & & & \\
\hline 4. Negative career goal discrepancy & 39.91 & 9.33 & $-.27 * * *$ & $-.23 * *$ & $-.48 * * *$ & & & \\
\hline 5. Age & 18.66 & .77 & .03 & -.01 & .02 & $-.14 *$ & & \\
\hline 6. Gender $(0=$ male, $1=$ female $)$ & - & - & -.03 & -.12 & -.09 & $-.15^{*}$ & -.07 & \\
\hline 7. SES $(1=$ much worse, $5=$ much better than others $)$ & 3.15 & .80 & $.15^{*}$ & .05 & $.17^{* *}$ & -.03 & -.11 & -.02 \\
\hline
\end{tabular}

Note. $* p<.05, * * p<.01, * * * p<.001$ 